\title{
Hybrid Methods for Equilibrium Problems and Fixed Points Problems of a Countable Family of Relatively Nonexpansive Mappings in Banach Spaces
}

\author{
Somyot Plubtieng and Wanna Sriprad \\ Department of Mathematics, Faculty of Science, Naresuan University, Phitsanulok 65000, Thailand \\ Correspondence should be addressed to Somyot Plubtieng, somyotp@nu.ac.th \\ Received 1 August 2009; Accepted 19 November 2009 \\ Academic Editor: Tomonari Suzuki \\ Copyright (C) 2010 S. Plubtieng and W. Sriprad. This is an open access article distributed under \\ the Creative Commons Attribution License, which permits unrestricted use, distribution, and \\ reproduction in any medium, provided the original work is properly cited. \\ The purpose of this paper is to introduce hybrid projection algorithms for finding a common \\ element of the set of common fixed points of a countable family of relatively nonexpansive \\ mappings and the set of solutions of an equilibrium problem in the framework of Banach spaces. \\ Moreover, we apply our result to the problem of finding a common element of an equilibrium \\ problem and the problem of finding a zero of a maximal monotone operator. Our result improve \\ and extend the corresponding results announced by Takahashi and Zembayashi (2008 and 2009), \\ and many others.
}

\section{Introduction}

Let $E$ be a real Banach space and $E^{*}$ the dual space of $E$. Let $C$ be a nonempty closed convex subset of $E$ and $f$ a bifunction from $C \times C$ to $\mathbb{R}$, where $\mathbb{R}$ denotes the set of real numbers. The equilibrium problem is to find $p \in C$ such that

$$
f(p, y) \geq 0, \quad \forall y \in C
$$

The set of solutions of (1.1) is denoted by $\operatorname{EP}(f)$. Given a mapping $T: C \rightarrow E^{*}$, let $f(x, y)=$ $\langle T x, y-x\rangle$ for all $x, y \in C$. Then, $p \in \operatorname{EP}(f)$ if and only if $\langle T p, y-p\rangle \geq 0$ for all $y \in C$, that is, $p$ is a solution of the variational inequality. Numerous problems in physics, optimization, and economics reduced to find a solution of (1.1). Some methods have been proposed to solve the 
equilibrium problem; see, for instance, Blum and Oettli [1], Combettes and Hirstoaga [2], and Moudafi [3].

Recall that a mapping $S: C \rightarrow C$ is said to be nonexpansive if

$$
\|S x-S y\| \leq\|x-y\|, \quad \forall x, y \in C
$$

We denote by $F(S)$ the set of fixed points of $S$. If a Banach space $E$ is uniformly convex, $C \subset E$ is bounded, closed and convex, and $S$ is a nonexpansive mapping of $C$ into itself, then $F(S)$ is nonempty; see [4] for more details. Recently, many authors studied the problem of finding a common element of the set of fixed points of a nonexpansive mapping and the set of solutions of an equilibrium problem in the framework of Hilbert spaces and Banach spaces, respectively; see, for instance, [5-13] and the references therein.

A popular method is the hybrid projection method developed by Nakajo and Takahashi [14], Kamimura and Takahashi [15], and Martinez-Yanes and Xu [16]; see also [5, 17-20] and references therein. Recently Takahashi et al. [21] introduced an alterative projection method, which is called the shrinking projection method, and they showed several strong convergence theorems for a family of nonexpansive mappings. In 2008, Takahashi and Zembayashi [12] introduced two iterative sequences for finding a common element of the set of fixed points of a relatively nonexpansive mapping and the set of solution of an equilibrium problem in a Banach space. Then they prove strong and weak convergence of the sequences. Very recently, Takahashi and Zembayashi [13] proved a strong convergence theorem for finding a common element of the set of solutions of an equilibrium problem and the set of fixed points of a relatively nonexpansive mapping in a Banach space by using a new hybrid method.

On the other hand, motivated by Nakajo and Takahashi [14], Matsushita and Takahashi [17] reformulated the definition of the notion and obtained weak and strong convergence theorems to approximate a fixed point of a single relatively nonexpansive mapping. Very recently, Aoyama et al. [22] introduce a Halpern type iterative sequence for finding a common fixed point of a countable family of nonexpansive mappings. Let $x_{1}=x \in C$ and

$$
x_{n+1}=\alpha_{n} x+\left(1-\alpha_{n}\right) T_{n} x_{n}
$$

for all $n \in \mathbb{N}$, where $C$ is a nonempty closed convex subset of a Banach space; $\left\{\alpha_{n}\right\}$ is a sequence in $[0,1]$, and $\left\{T_{n}\right\}$ is a sequence of nonexpansive mappings with some condition. They proved that $\left\{x_{n}\right\}$ defined by (1.3) converges strongly to a common fixed point of $\left\{T_{n}\right\}$.

Motivated and inspired by the research going on in this direction, we prove a strong convergence theorem for finding a common element of the set of solutions of an equilibrium problem and the set of common fixed points of a countable family of relatively nonexpansive mappings in a Banach space by using the shrinking projection method. Further, we apply our result to the problem of finding a common element of an equilibrium problem and the problem of finding a zero of a maximal monotone operator. The result obtained in this paper improves and extends the corresponding result of [13] and many others. 


\section{Preliminaries}

Let $E$ be a real Banach space with norm $\|\cdot\|$ and let $E^{*}$ be the dual of $E$. For all $x \in E$ and $x^{*} \in E^{*}$, we denote the value of $x^{*}$ at $x$ by $\left\langle x, x^{*}\right\rangle$. The normalized duality mapping $J$ from $E$ to $E^{*}$ is defined by

$$
J x=\left\{x^{*} \in E^{*}:\left\langle x, x^{*}\right\rangle=\|x\|^{2}=\left\|x^{*}\right\|^{2}\right\}
$$

for $x \in E$. By Hahn-Banach theorem, $J(x)$ is nonempty; see [4] for more details. We denote the strong convergence and the weak convergence of a sequence $\left\{x_{n}\right\}$ to $x$ in $E$ by $x_{n} \rightarrow x$ and $x_{n} \rightarrow x$, respectively. We also denote the weak convergence of a sequence $\left\{x_{n}^{*}\right\}$ to $x^{*}$ in $E^{*}$ by $x_{n}^{*}-{ }^{*} x^{*}$. A Banach space $E$ is said to be strictly convex if $\|(x+y) / 2\|<1$ for all $x, y \in E$ with $\|x\|=\|y\|=1$ and $x \neq y$. It is also said to be uniformly convex if for each $\varepsilon \in(0,2]$, there exists $\delta>0$ such that $\|x+y\| / 2 \leq 1-\delta$ for $x, y \in E$ with $\|x\|=\|y\|=1$ and $\|x-y\| \geq \varepsilon$. A uniformly convex Banach space has the Kadec-Klee property, that is, $x_{n}-x$ and $\left\|x_{n}\right\| \rightarrow\|x\|$ imply $x_{n} \rightarrow x$. Let $S(E)=\{x \in E:\|x\|=1\}$ be the unit sphere of $E$. Then the Banach space $E$ is said to be smooth provided that

$$
\lim _{t \rightarrow 0} \frac{\|x+t y\|-\|x\|}{t}
$$

exists for each $x, y \in S(E)$. It is also said to be uniformly smooth if the limit is attained uniformly for $x, y \in S(E)$. It is well know that if $E$ is smooth, strictly convex and reflexive, then the duality mapping $J$ is single valued, one-to-one and onto.

Let $E$ be a smooth, strictly convex and reflexive Banach space, and let $C$ be a nonempty closed convex subset of $E$. Throughout this paper, we denote by $\phi$ the function defined by

$$
\phi(y, x)=\|y\|^{2}-2\langle y, J x\rangle+\|x\|^{2} \quad \forall x, y \in C .
$$

It is obvious from the definition of the function $\phi$ that $(\|x\|-\|y\|)^{2} \leqslant \phi(y, x) \leqslant\left(\|y\|^{2}+\|x\|^{2}\right)$, for all $x, y \in E$. Following Alber [23], the generalized projection $\Pi_{C}$ from $E$ onto $C$ is defined by

$$
\Pi_{C}(x)=\arg \min _{y \in C} \phi(y, x), \quad \forall x \in E .
$$

If $E$ is a Hilbert space, then $\phi(y, x)=\|y-x\|^{2}$ and $\Pi_{C}$ is the metric projection of $H$ onto $C$. We know the following lemmas for generalized projections.

Lemma 2.1 (Alber [23], Kamimura and Takahashi [15]). Let $C$ be a nonempty closed convex subset of a smooth, strictly convex and reflexive Banach space $E$. Then

$$
\phi\left(x, \Pi_{C} y\right)+\phi\left(\Pi_{C} y, y\right) \leq \phi(x, y), \quad \forall x \in C, y \in E .
$$


Lemma 2.2 (Alber [23], Kamimura and Takahashi [15]). Let $C$ be a nonempty closed convex subset of a smooth, strictly convex and reflexive Banach space $E$; let $x \in E$, and let $z \in C$. Then

$$
z=\Pi_{C} x \Longleftrightarrow\langle y-z, J x-J z\rangle \leq 0, \quad \forall y \in C
$$

Let $C$ be a nonempty closed convex subset of a smooth, strictly convex and reflexive Banach space $E$; let $T$ be a mapping from $C$ into itself. We denote by $F(T)$ the set of fixed point of $T$. A point $p \in C$ is said to be an asymptotic fixed point of $T$ if there exists $\left\{x_{n}\right\}$ in $C$ which converges weakly to $p$ and $\lim _{n \rightarrow \infty}\left\|x_{n}-T x_{n}\right\|=0$. The set of asymptotic fixed points of $T$ will be denoted by $\widehat{F}(T)$. Following Matsushita and Takahashi [17], a mapping $T$ from $C$ into itself is said to be relatively nonexpansive if $F(T)$ is nonempty, $\phi(u, T x) \leq \phi(u, x)$, for all $u \in$ $F(T), x \in C$, and $\widehat{F}(T)=F(T)$.

The following lemma is according to Matsushita and Takahashi [17].

Lemma 2.3 (Matsushita and Takahashi [17]). Let $C$ be a nonempty closed convex subset of a smooth, strictly convex and reflexive Banach space $E$, and let $T$ be a relatively nonexpansive mapping from $C$ into itself. Then $F(T)$ is closed and convex.

We also know the following three lemmas.

Lemma 2.4 (Kamimura and Takahashi [15]). Let E be a uniformly convex and smooth Banach space, and let $\left\{x_{n}\right\},\left\{y_{n}\right\}$ be sequences in $E$ such that either $\left\{x_{n}\right\}$ or $\left\{y_{n}\right\}$ is bounded. If $\lim _{n \rightarrow \infty} \phi\left(x_{n}, y_{n}\right)=0$, then $\lim _{n \rightarrow \infty}\left\|x_{n}-y_{n}\right\|=0$.

Lemma 2.5 (Xu [24], Zălinescu [25, 26]). Let E be a uniformly convex Banach space, and let $r>0$. Then there exists a strictly increasing, continuous, and convex function $g:[0,2 r] \rightarrow \mathbb{R}$ such that $g(0)=0$ and

$$
\|t x+(1-t) y\|^{2} \leq t\|x\|^{2}+(1-t)\|y\|^{2}-t(1-t) g(\|x-y\|),
$$

for all $x, y \in B_{r}$ and $t \in[0,1]$, where $B_{r}=\{z \in E:\|z\| \leq r\}$.

Lemma 2.6 (Kamimura and Takahashi [15]). Let $E$ be a smooth and uniformly convex Banach space and let $r>0$. Then there exists a strictly increasing, continuous, and convex function $g$ : $[0,2 r] \rightarrow \mathbb{R}$ such that $g(0)=0$ and

$$
g(\|x-y\|) \leq \phi(x, y)
$$

for all $x, y \in B_{r}$.

For solving the equilibrium problem, let us assume that a bifunction $f$ satisfies the following conditions:

(A1) $f(x, x)=0$ for all $x \in C$;

(A2) $f$ is monotone, that is, $f(x, y)+f(y, x) \leq 0$ for all $x, y \in C$; 
Fixed Point Theory and Applications

(A3) for each $x, y, z \in C$,

$$
\lim _{t \rightarrow 0^{+}} f(t z+(1-t) x, y) \leq f(x, y)
$$

(A4) for each $x \in C, y \mapsto f(x, y)$ is convex and lower semicontinuous.

The following result is in Blum and Oettlli [1].

Lemma 2.7 (Blum and Oettlli [1]). Let $C$ be a nonempty closed convex subset of a smooth, strictly convex and reflexive Banach space $E$, and let $f$ be a bifunction from $C \times C \rightarrow \mathbb{R}$ satisfying (A1)-(A4), and let $r>0$ and $x \in E$. Then, there exists $z \in C$ such that

$$
f(z, y)+\frac{1}{r}\langle y-z, J z-J x\rangle \geq 0, \quad \forall y \in C
$$

We also know the following lemmas.

Lemma 2.8 (Takahashi and Zembayashi [12]). Let $C$ be a nonempty closed convex subset of a uniformly smooth, strictly convex and reflexive Banach space $E$, and let $f$ be a bifunction from $C \times C \rightarrow$ $\mathbb{R}$ satisfying $(A 1)-(A 4)$. For $r>0$ and $x \in E$, define a mapping $T_{r}: E \rightarrow C$ as follows:

$$
T_{r}(x)=\left\{z \in C: f(z, y)+\frac{1}{r}\langle y-z, J z-J x\rangle \geq 0, \forall y \in C\right\}
$$

for all $x \in E$, Then, the following holds:

(1) $T_{r}$ is single-valued;

(2) $T_{r}$ is a firmly nonexpansive-type mapping, that is, for all $x, y \in E$,

$$
\left\langle T_{r} x-T_{r} y, J T_{r} x-J T_{r} y\right\rangle \leq\left\langle T_{r} x-T_{r} y, J x-J y\right\rangle
$$

(3) $F\left(T_{r}\right)=\widehat{F}\left(T_{r}\right)=\mathrm{EP}(f)$;

(4) $\mathrm{EP}(f)$ is closed and convex.

Lemma 2.9 (Takahashi and Zembayashi [12]). Let $C$ be a nonempty closed convex subset of a smooth, strictly convex and reflexive Banach space $E$, and let $f$ be a bifunction from $C \times C \rightarrow \mathbb{R}$ satisfying (A1)-(A4). Then for $r>0, x \in E$, and $q \in F\left(T_{r}\right)$,

$$
\phi\left(q, T_{r} x\right)+\phi\left(T_{r} x, x\right) \leq \phi(q, x)
$$




\section{Main Results}

Let $C$ be a nonempty closed convex subset of a Banach space $E$; let $\left\{T_{n}\right\}$ be a family of mappings of $C$ into itself with $F:=\bigcap_{n=1}^{\infty} F\left(T_{n}\right) \neq \emptyset$ and $\omega_{w}\left(z_{n}\right)$ denotes the set of all weak subsequential limits of a bounded sequence $\left\{z_{n}\right\}$ in $C$. $\left\{T_{n}\right\}$ is said to satisfy the NST*condition [27] if for every bounded sequence $\left\{z_{n}\right\}$ in $C$,

$$
\lim _{n \rightarrow \infty}\left\|z_{n+1}-z_{n}\right\|=\lim _{n \rightarrow \infty}\left\|z_{n}-T_{n} z_{n}\right\|=0 \text { implies } \omega_{w}\left(z_{n}\right) \subset F .
$$

In this section, by using the NST*-condition, we prove two strong convergence theorems for finding a common element of the set of solutions of an equilibrium problem and the set of fixed points of a countable family of relatively nonexpansive mappings in a Banach space.

Theorem 3.1. Let $E$ be a uniformly convex and uniformly smooth Banach space, and let $C$ be a nonempty closed convex subset of $E$. Let $f$ be a bifunction from $C \times C$ to $\mathbb{R}$ satisfying $(A 1)-(A 4)$, and let $\left\{S_{n}\right\}$ be a family of relatively nonexpansive mappings from $C$ into itself such that $\Omega:=\left(\bigcap_{n=1}^{\infty} F\left(S_{n}\right)\right) \cap$ $\mathrm{EP}(f) \neq \emptyset$. Let $\left\{x_{n}\right\}$ be a sequence generated by $x_{0}=x \in C, C_{0}=C$, and

$$
\begin{gathered}
y_{n}=J^{-1}\left(\alpha_{n} J x_{n}+\left(1-\alpha_{n}\right) J S_{n} x_{n}\right), \\
u_{n} \in C \text { such that } f\left(u_{n}, y\right)+\frac{1}{r_{n}}\left\langle y-u_{n}, J u_{n}-J y_{n}\right\rangle \geq 0, \quad \forall y \in C, \\
C_{n+1}=\left\{z \in C_{n}: \phi\left(z, u_{n}\right) \leqslant \phi\left(z, x_{n}\right)\right\}, \\
x_{n+1}=\prod_{C_{n+1}} x,
\end{gathered}
$$

for every $n \in \mathbb{N} \cup\{0\}$, where $J$ is the duality mapping on $E,\left\{\alpha_{n}\right\} \subset[0,1]$ satisfies $\lim _{\inf } f_{n \rightarrow \infty} \alpha_{n}(1-$ $\left.\alpha_{n}\right)>0$ and $\left\{r_{n}\right\} \subset[a, \infty)$ for some $a>0$. Suppose that $\left\{S_{n}\right\}$ satisfy the NST*-condition. Then $\left\{x_{n}\right\}$ converges strongly to $\Pi_{\Omega} x$, where $\Pi_{\Omega}$ is the generalized projection of $E$ onto $\Omega:=\left(\bigcap_{n=1}^{\infty} F\left(S_{n}\right)\right) \cap$ $\mathrm{EP}(f)$.

Proof. Putting $u_{n}=T_{r_{n}} y_{n}$ for all $n \in \mathbb{N}$, we have from Lemma 2.9 that $T_{r_{n}}$ are relatively nonexpansive.

We first show that $C_{n}$ is closed and convex. It is obvious that $C_{n}$ is closed. Since

$$
\phi\left(z, u_{n}\right) \leq \phi\left(z, x_{n}\right) \Longleftrightarrow\left\|u_{n}\right\|^{2}-\left\|x_{n}\right\|^{2}-2\left\langle z, J u_{n}-J x_{n}\right\rangle \geq 0,
$$

$C_{n}$ is convex. So, $C_{n}$ is a closed convex subset of $E$ for all $n \in \mathbb{N} \cup\{0\}$.

Next, we show by induction that $\Omega:=\left(\bigcap_{n=1}^{\infty} F\left(S_{n}\right) \cap \operatorname{EP}(f) \subset C_{n}\right.$ for all $n \in \mathbb{N} \cup\{0\}$. From $C_{0}=C$, we have $\Omega \subset C_{0}$. Suppose that $\Omega \subset C_{k}$ for some $k \in \mathbb{N} \cup\{0\}$. Let $u \in \Omega \subset C_{k}$. 
Since $T_{r_{k}}$ and $S_{k}$ are relatively nonexpansive, it follows that

$$
\begin{aligned}
\phi\left(u, u_{k}\right) & =\phi\left(u, T_{r_{k}} y_{k}\right) \leq \phi\left(u, y_{k}\right) \\
& =\phi\left(u, J^{-1}\left(\alpha_{k} J x_{k}+\left(1-\alpha_{k}\right) J S_{k} x_{k}\right)\right) \\
& =\|u\|^{2}-2\left\langle u, \alpha_{k} J x_{k}+\left(1-\alpha_{k}\right) J S_{k} x_{k}\right\rangle+\left\|\alpha_{k} J x_{k}+\left(1-\alpha_{k}\right) J S_{k} x_{k}\right\|^{2} \\
& \leq\|u\|^{2}-2 \alpha_{k}\left\langle u, J x_{k}\right\rangle-2\left(1-\alpha_{k}\right)\left\langle u, J S_{k} x_{k}\right\rangle+\alpha_{k}\left\|x_{k}\right\|^{2}+\left(1-\alpha_{k}\right)\left\|S_{k} x_{k}\right\|^{2} \\
& =\alpha_{k} \phi\left(u, x_{k}\right)+\left(1-\alpha_{k}\right) \phi\left(u, S_{k} x_{k}\right) \leq \phi\left(u, x_{k}\right) .
\end{aligned}
$$

Hence $u \in C_{k+1}$. This implies that $\Omega \subset C_{n}$ for all $n \in \mathbb{N} \cup\{0\}$. So, $\left\{x_{n}\right\}$ is well defined.

Next, we show that $\left\{x_{n}\right\}$ is bounded. From the definition of $x_{n}$, we have

$$
\phi\left(x_{n}, x\right)=\phi\left(\Pi_{C_{n}} x, x\right) \leq \phi(u, x)-\phi\left(u, \Pi_{C_{n}} x\right) \leq \phi(u, x),
$$

for all $u \in \Omega \subset C_{n}$. Thus $\left\{\phi\left(x_{n}, x\right)\right\}$ is bounded and therefore $\left\{x_{n}\right\}$ and $\left\{S_{n} x_{n}\right\}$ are also bounded.

From $x_{n+1} \in C_{n+1} \subset C_{n}$ and $x_{n}=\Pi_{C_{n}} x$, we have

$$
\phi\left(x_{n}, x\right) \leq \phi\left(x_{n+1}, x\right), \quad \forall n \in \mathbb{N} \cup\{0\}
$$

This implies that $\left\{\phi\left(x_{n}, x\right)\right\}$ is nondecreasing and so $\lim _{n \rightarrow \infty} \phi\left(x_{n}, x\right)$ exists. Since

$$
\phi\left(x_{n+1}, x_{n}\right)=\phi\left(x_{n+1}, \Pi_{C_{n}} x\right) \leq \phi\left(x_{n+1}, x\right)-\phi\left(\Pi_{C_{n}} x, x\right) \leq \phi\left(x_{n+1}, x\right)-\phi\left(x_{n}, x\right),
$$

for all $n \in \mathbb{N} \cup\{0\}$, it follows that $\lim _{n \rightarrow \infty} \phi\left(x_{n+1}, x_{n}\right)=0$. From $x_{n+1}=\prod_{C_{n+1}} x \in C_{n+1}$, we have

$$
\phi\left(x_{n+1}, u_{n}\right) \leq \phi\left(x_{n+1}, x_{n}\right), \quad \forall n \in \mathbb{N} \cup\{0\} .
$$

Therefore, we also have

$$
\lim _{n \rightarrow \infty} \phi\left(x_{n+1}, u_{n}\right)=0
$$

Since $\lim _{n \rightarrow \infty} \phi\left(x_{n+1}, x_{n}\right)=\lim _{n \rightarrow \infty} \phi\left(x_{n+1}, u_{n}\right)=0$ and $E$ is uniformly convex and smooth, it follows from Lemma 2.4 that

$$
\lim _{n \rightarrow \infty}\left\|x_{n+1}-x_{n}\right\|=\lim _{n \rightarrow \infty}\left\|x_{n+1}-u_{n}\right\|=0 .
$$

Thus, we have

$$
\lim _{n \rightarrow \infty}\left\|x_{n}-u_{n}\right\|=0
$$


Since $J$ is uniformly norm-to-norm continuous on bounded sets, it follows by (3.11) that

$$
\lim _{n \rightarrow \infty}\left\|J x_{n}-J u_{n}\right\|=0 .
$$

Let $r=\sup _{n \in \mathbb{N}}\left\{\left\|x_{n}\right\|,\left\|S_{n} x_{n}\right\|\right\}$. Since $E$ is a uniformly smooth Banach space, we note that $E^{*}$ is a uniformly convex Banach space. Therefore, by Lemma 2.5, there exists a continuous, strictly increasing, and convex function $g$ with $g(0)=0$ such that

$$
\left\|\alpha x^{*}+(1-\alpha) y^{*}\right\|^{2} \leq \alpha\left\|x^{*}\right\|^{2}+(1-\alpha)\left\|y^{*}\right\|^{2}-\alpha(1-\alpha) g\left(\left\|x^{*}-y^{*}\right\|\right)
$$

for $x^{*}, y^{*} \in B_{r}^{*}=\left\{z \in E^{*}:\|z\| \leq r\right\}$ and $\alpha \in[0,1]$. So, we have

$$
\begin{aligned}
\phi\left(u, u_{n}\right)= & \phi\left(u, T_{r_{n}} y_{n}\right) \leq \phi\left(u, y_{n}\right)=\phi\left(u, J^{-1}\left(\alpha_{n} J x_{n}+\left(1-\alpha_{n}\right) J S_{n} x_{n}\right)\right) \\
= & \|u\|^{2}-2\left\langle u, \alpha_{n} J x_{n}+\left(1-\alpha_{n}\right) J S_{n} x_{n}\right\rangle+\left\|\alpha_{n} J x_{n}+\left(1-\alpha_{n}\right) J S_{n} x_{n}\right\|^{2} \\
\leq & \|u\|^{2}-2 \alpha_{n}\left\langle u, J x_{n}\right\rangle-2\left(1-\alpha_{n}\right)\left\langle u, J S_{n} x_{n}\right\rangle+\alpha_{n}\left\|x_{n}\right\|^{2}+\left(1-\alpha_{n}\right)\left\|S_{n} x_{n}\right\|^{2} \\
& -\alpha_{n}\left(1-\alpha_{n}\right) g\left(\left\|J x_{n}-J S_{n} x_{n}\right\|\right) \\
= & \alpha_{n} \phi\left(u, x_{n}\right)+\left(1-\alpha_{n}\right) \phi\left(u, S_{n} x_{n}\right)-\alpha_{n}\left(1-\alpha_{n}\right) g\left(\left\|J x_{n}-J S_{n} x_{n}\right\|\right) \\
\leq & \phi\left(u, x_{n}\right)-\alpha_{n}\left(1-\alpha_{n}\right) g\left(\left\|J x_{n}-J S_{n} x_{n}\right\|\right)
\end{aligned}
$$

for all $u \in \Omega$. Therefore, we have

$$
\alpha_{n}\left(1-\alpha_{n}\right) g\left(\left\|J x_{n}-J S_{n} x_{n}\right\|\right) \leq \phi\left(u, x_{n}\right)-\phi\left(u, u_{n}\right), \quad \forall n \in \mathbb{N} \cup\{0\} .
$$

Since

$$
\begin{aligned}
\phi\left(u, x_{n}\right)-\phi\left(u, u_{n}\right) & =\left\|x_{n}\right\|^{2}-\left\|u_{n}\right\|^{2}-2\left\langle u, J x_{n}-J u_{n}\right\rangle \\
& \leq\left|\left\|x_{n}\right\|^{2}-\left\|u_{n}\right\|^{2}\right|+2\left|\left\langle u, J x_{n}-J u_{n}\right\rangle\right| \\
& \leq\left|\left(\left\|x_{n}\right\|-\left\|u_{n}\right\|\right)\left(\left\|x_{n}\right\|+\left\|u_{n}\right\|\right)\right|+2\|u\|\left\|J x_{n}-J u_{n}\right\| \\
& \leq\left|\left\|x_{n}-u_{n}\right\|\left(\left\|x_{n}\right\|+\left\|u_{n}\right\|\right)\right|+2\|u\|\left\|J x_{n}-J u_{n}\right\|,
\end{aligned}
$$

it follows that

$$
\lim _{n \rightarrow \infty}\left(\phi\left(u, x_{n}\right)-\phi\left(u, u_{n}\right)\right)=0 .
$$

From $\liminf _{n \rightarrow \infty} \alpha_{n}\left(1-\alpha_{n}\right)>0$, we have

$$
\lim _{n \rightarrow \infty} g\left(\left\|J x_{n}-J S_{n} x_{n}\right\|\right)=0 .
$$


Fixed Point Theory and Applications

Therefore, we note from the property of $g$ that

$$
\lim _{n \rightarrow \infty}\left\|J x_{n}-J S_{n} x_{n}\right\|=0
$$

Since $J^{-1}$ is uniformly norm-to-norm continuous on bounded sets, it follows that

$$
\lim _{n \rightarrow \infty}\left\|x_{n}-S_{n} x_{n}\right\|=\lim _{n \rightarrow \infty}\left\|J^{-1} J x_{n}-J^{-1} J S_{n} x_{n}\right\|=0 .
$$

Since $\left\{S_{n}\right\}$ satisfy the NST*-condition, we have $\omega_{w}\left(x_{n}\right) \subset F:=\bigcap_{n=1}^{\infty} F\left(S_{n}\right)$. So, we assume that a subsequence $\left\{x_{n_{k}}\right\}$ of $\left\{x_{n}\right\}$ converges weakly to $\hat{x} \in F$. We shall show that $\hat{x} \in \operatorname{EP}(f)$. From $u_{n}=T_{r_{n}} y_{n}$ and Lemma 2.9, we have

$$
\begin{aligned}
\phi\left(u_{n}, y_{n}\right) & =\phi\left(T_{r_{n}} y_{n}, y_{n}\right) \leq \phi\left(u, y_{n}\right)-\phi\left(u, T_{r_{n}} y_{n}\right) \\
& \leq \phi\left(u, x_{n}\right)-\phi\left(u, T_{r_{n}} y_{n}\right)=\phi\left(u, x_{n}\right)-\phi\left(u, u_{n}\right) .
\end{aligned}
$$

So, we note from (3.17) that

$$
\lim _{n \rightarrow \infty} \phi\left(u_{n}, y_{n}\right)=0
$$

Since $E$ is uniformly convex and smooth and $\left\{u_{n}\right\}$ is bounded, it follows from Lemma 2.4 that

$$
\lim _{n \rightarrow \infty}\left\|u_{n}-y_{n}\right\|=0
$$

From $x_{n_{k}} \rightarrow \widehat{x},\left\|u_{n}-y_{n}\right\| \rightarrow 0$ and $\left\|x_{n}-u_{n}\right\| \rightarrow 0$, we have $y_{n_{k}} \rightarrow \widehat{x}$. Since $J$ is uniformly norm-to-norm continuous on bounded sets and (3.23), it follows that

$$
\lim _{n \rightarrow \infty}\left\|J u_{n}-J y_{n}\right\|=0
$$

From $r_{n} \geq a$, we have

$$
\lim _{n \rightarrow \infty} \frac{\left\|J u_{n}-J y_{n}\right\|}{r_{n}}=0 .
$$

By the definition of $u_{n}=T_{r_{n}} y_{n}$, we have

$$
f\left(u_{n}, y\right)+\frac{1}{r_{n}}\left\langle y-u_{n}, J u_{n}-J y_{n}\right\rangle \geq 0, \quad \forall y \in C .
$$

Replacing $n$ by $n_{k}$, we have from (A2) that

$$
\frac{1}{r_{n_{k}}}\left\langle y-u_{n_{k}}, J u_{n_{k}}-J y_{n_{k}}\right\rangle \geq f\left(y, u_{n_{k}}\right), \quad \forall y \in C
$$


Since $f(x, \cdot)$ is convex and lower semicontinuous, it is also weakly lower semicontinuous. Letting $k \rightarrow \infty$, we note from (3.25) and (A4) that

$$
f(y, \widehat{x}) \leq \liminf _{k \rightarrow \infty} f\left(y, u_{n_{k}}\right) \leq \liminf _{k \rightarrow \infty}\left\langle y-u_{n_{k}}, \frac{J u_{n_{k}}-J y_{n_{k}}}{r_{n_{k}}}\right\rangle=0, \quad \forall y \in C .
$$

For $t$ with $0<t \leq 1$ and $y \in C$, let $y_{t}=t y+(1-t) \widehat{x}$. Since $y \in C$ and $\widehat{x} \in C$, we have $y_{t} \in C$ and hence $f\left(y_{t}, \widehat{x}\right) \leq 0$. So, from (A1), we have

$$
0=f\left(y_{t}, y_{t}\right) \leq t f\left(y_{t}, y\right)+(1-t) f\left(y_{t}, \widehat{x}\right) \leq t f\left(y_{t}, y\right)
$$

This implies that

$$
f\left(y_{t}, y\right) \geq 0, \quad \forall y \in C
$$

Letting $t \rightarrow 0^{+}$from (A3), we have

$$
f(\widehat{x}, y) \geq 0, \quad \forall y \in C
$$

Therefore, we obtain $\hat{x} \in \operatorname{EP}(f)$. Finally, we will show that $x_{n} \rightarrow \Pi_{\Omega} x$. Let $w=\Pi_{\Omega} x$. From $x_{n}=\Pi_{C_{n}} x$ and $w \in \Omega \subset C_{n}$, we note that

$$
\phi\left(x_{n}, x\right) \leq \phi(w, x)
$$

Since the norm is weakly lower semicontinuous, it follows that

$$
\begin{aligned}
\phi(\widehat{x}, x) & =\|\widehat{x}\|^{2}-2\langle\widehat{x}, J x\rangle+\|x\|^{2} \\
& \leq \liminf _{k \rightarrow \infty}\left(\left\|x_{n_{k}}\right\|^{2}-2\left\langle x_{n_{k}}, J x\right\rangle+\|x\|^{2}\right) \\
& =\liminf _{k \rightarrow \infty} \phi\left(x_{n_{k}}, x\right) \\
& \leq \limsup _{k \rightarrow \infty} \phi\left(x_{n_{k}}, x\right) \leq \phi(w, x) .
\end{aligned}
$$

From the definition of $\Pi_{\Omega}$, we have $\widehat{x}=w$. Hence $\lim _{k \rightarrow \infty} \phi\left(x_{n_{k}}, x\right)=\phi(w, x)$. Therefore, we obtain

$$
\begin{aligned}
0 & =\lim _{k \rightarrow \infty}\left(\phi\left(x_{n_{k}}, x\right)-\phi(w, x)\right) \\
& =\lim _{k \rightarrow \infty}\left(\left\|x_{n_{k}}\right\|^{2}-\|w\|^{2}-2\left\langle x_{n_{k}}-w, J x\right\rangle\right) \\
& =\lim _{k \rightarrow \infty}\left(\left\|x_{n_{k}}\right\|^{2}-\|w\|^{2}\right) .
\end{aligned}
$$


Since $E$ has the Kadec-Klee property, it follows that $x_{n_{k}} \rightarrow w=\Pi_{\Omega}$. Therefore, $\left\{x_{n}\right\}$ converges strongly to $\Pi_{\Omega} x$.

As direct consequences of Theorem 3.1, we can obtain the following corollaries.

Corollary 3.2 (Takahashi and Zembayashi [13]). Let E be a uniformly convex and uniformly smooth Banach space, and let $C$ be a nonempty closed convex subset of $E$. Let $f$ be a bifunction from $C \times C$ to $\mathbb{R}$ satisfying $(A 1)-(A 4)$, and let $S$ be a relatively nonexpansive mapping from $C$ into itself such that $\Omega:=F(S) \cap \operatorname{EP}(f) \neq \emptyset$. Let $\left\{x_{n}\right\}$ be a sequence generated by $x_{0}=x \in C, C_{0}=C$, and

$$
\begin{gathered}
y_{n}=J^{-1}\left(\alpha_{n} J x_{n}+\left(1-\alpha_{n}\right) J S x_{n}\right), \\
u_{n} \in C \text { such that } f\left(u_{n}, y\right)+\frac{1}{r_{n}}\left\langle y-u_{n}, J u_{n}-J y_{n}\right\rangle \geq 0, \quad \forall y \in C, \\
C_{n+1}=\left\{z \in C_{n}: \phi\left(z, u_{n}\right) \leqslant \phi\left(z, x_{n}\right)\right\}, \\
x_{n+1}=\prod_{C_{n+1}} x,
\end{gathered}
$$

for every $n \in \mathbb{N} \cup\{0\}$, where $J$ is the duality mapping on $E,\left\{\alpha_{n}\right\} \subset[0,1]$ satisfies $\lim _{\inf } \operatorname{li}_{n \rightarrow \infty} \alpha_{n}(1-$ $\left.\alpha_{n}\right)>0$, and $\left\{r_{n}\right\} \subset[a, \infty)$ for some $a>0$. Then $\left\{x_{n}\right\}$ converges strongly to $\Pi_{\Omega}$, where $\Pi_{\Omega}$ is the generalized projection of $E$ onto $\Omega:=F(S) \cap \mathrm{EP}(f)$.

Proof. Put $S_{n} \equiv S$. Let $\left\{z_{n}\right\}$ be a bounded sequence in $C$ with $\lim _{n \rightarrow \infty}\left\|z_{n+1}-z_{n}\right\|=\lim _{n \rightarrow \infty} \| z_{n}-$ $S z_{n} \|=0$, and let $z \in \omega_{w}\left(z_{n}\right)$. Then there exists subsequence $\left\{z_{n_{k}}\right\}$ of $\left\{z_{n}\right\}$ such that $z_{n_{k}} \rightarrow z$. It follows directly from the definition of $S$ that $z \in \widehat{F}(S)=F(S)$. Hence $S$ satisfies NST*condition, by Theorem 3.1; $\left\{x_{n}\right\}$ converges strongly to $\Pi_{\Omega}$.

Corollary 3.3 (Takahashi and Zembayashi [12]). Let E be a uniformly convex and uniformly smooth Banach space; let $C$ be a nonempty closed convex subset of $E$. Let $f$ be a bifunction from $C \times C$ to $\mathbb{R}$ satisfying $(A 1)-(A 4)$. Let $\left\{x_{n}\right\}$ be a sequence generated by $x_{0}=x \in C, C_{0}=C$, and

$$
\begin{gathered}
u_{n} \in C \text { such that } f\left(u_{n}, y\right)+\frac{1}{r_{n}}\left\langle y-u_{n}, J u_{n}-J x_{n}\right\rangle \geq 0, \quad \forall y \in C, \\
C_{n+1}=\left\{z \in C_{n}: \phi\left(z, u_{n}\right) \leqslant \phi\left(z, x_{n}\right)\right\}, \\
x_{n+1}=\prod_{C_{n+1}} x,
\end{gathered}
$$

for every $n \in \mathbb{N} \cup\{0\}$, where $J$ is the duality mapping on $E$ and $\left\{r_{n}\right\} \subset[a, \infty)$ for some $a>0$. Then, $\left\{x_{n}\right\}$ converges strongly to $\Pi_{\mathrm{EP}(f)} x$.

Proof. Putting $S_{n} \equiv I$ in Theorem 3.1, we obtain Corollary 3.3.

Corollary 3.4. Let E be a uniformly convex and uniformly smooth Banach space, and let $C$ be a nonempty closed convex subset of $E$. Let $\left\{S_{n}\right\}$ be a family of relatively nonexpansive mappings from 
$C$ into itself such that $F:=\bigcap_{n=1}^{\infty} F\left(S_{n}\right) \neq \emptyset$. Let $\left\{x_{n}\right\}$ be a sequence generated by $x_{0}=x \in C, C_{0}=C$, and

$$
\begin{gathered}
y_{n}=\prod_{C} J^{-1}\left(\alpha_{n} J x_{n}+\left(1-\alpha_{n}\right) J S_{n} x_{n}\right), \\
C_{n+1}=\left\{z \in C_{n}: \phi\left(z, y_{n}\right) \leqslant \phi\left(z, x_{n}\right)\right\}, \\
x_{n+1}=\prod_{C_{n+1}} x,
\end{gathered}
$$

for every $n \in \mathbb{N} \cup\{0\}$, where $J$ is the duality mapping on $E,\left\{\alpha_{n}\right\} \subset[0,1]$ satisfies $\lim _{\inf } \operatorname{si\infty }_{n \rightarrow \infty} \alpha_{n}(1-$ $\left.\alpha_{n}\right)>0$. Suppose that $\left\{S_{n}\right\}$ satisfy the NST*-condition. Then $\left\{x_{n}\right\}$ converges strongly to $\Pi_{F}$, where $\Pi_{F}$ is the generalized projection of $E$ onto $F:=\bigcap_{n=1}^{\infty} F\left(S_{n}\right)$.

Proof. Putting $f(x, y)=0$ for all $x, y \in C$ and $r_{n}=1$ in Theorem 3.1, we obtain Corollary 3.4.

Similarly as in the proof of Theorem 3.1, we can prove the following theorem.

Theorem 3.5. Let $E$ be a uniformly convex and uniformly smooth Banach space, and let $C$ be a nonempty closed convex subset of $E$. Let $f$ be a bifunction from $C \times C$ to $\mathbb{R}$ satisfying $(A 1)-(A 4)$ and let $\left\{S_{n}\right\}$ be a family of relatively nonexpansive mappings from $C$ into itself such that $\Omega:=\left(\bigcap_{n=1}^{\infty} F\left(S_{n}\right)\right) \cap$ $\mathrm{EP}(f) \neq \emptyset$. Let $\left\{x_{n}\right\}$ be a sequence generated by $x_{0}=x \in C$ and

$$
\begin{gathered}
y_{n}=J^{-1}\left(\alpha_{n} J x_{n}+\left(1-\alpha_{n}\right) J S_{n} x_{n}\right), \\
u_{n} \in C \text { such that } f\left(u_{n}, y\right)+\frac{1}{r_{n}}\left\langle y-u_{n}, J u_{n}-J y_{n}\right\rangle \geq 0, \quad \forall y \in C, \\
H_{n}=\left\{z \in C: \phi\left(z, u_{n}\right) \leqslant \phi\left(z, x_{n}\right)\right\}, \\
W_{n}=\left\{z \in C:\left\langle x_{n}-z, J x-J x_{n}\right\rangle \geq 0\right\}, \\
x_{n+1}=\Pi_{H_{n} \cap W_{n}} x,
\end{gathered}
$$

for every $n \in \mathbb{N} \cup\{0\}$, where $J$ is the duality mapping on $E,\left\{\alpha_{n}\right\} \subset[0,1]$ satisfies $\lim _{\inf } \sin _{n \rightarrow \infty} \alpha_{n}(1-$ $\left.\alpha_{n}\right)>0$ and $\left\{r_{n}\right\} \subset[a, \infty)$ for some $a>0$. Suppose that $\left\{S_{n}\right\}$ satisfy the NST*-condition. Then $\left\{x_{n}\right\}$ converges strongly to $\Pi_{\Omega} x$, where $\Pi_{\Omega}$ is the generalized projection of $E$ onto $\Omega:=\left(\bigcap_{n=1}^{\infty} F\left(S_{n}\right)\right) \cap$ $\mathrm{EP}(f)$.

Proof. We first show that $H_{n} \cap W_{n}$ is closed and convex. It is obvious that $H_{n}$ is closed and $W_{n}$ is closed and convex. Since $\phi\left(z, u_{n}\right) \leq \phi\left(z, x_{n}\right) \Leftrightarrow\left\|u_{n}\right\|^{2}-\left\|x_{n}\right\|^{2}-2\left\langle z, J u_{n}-J x_{n}\right\rangle \geq 0$, it follows that $H_{n}$ is convex. Hence $H_{n} \cap W_{n}$ is a closed and convex subset of $E$ for all $n \in \mathbb{N} \cup\{0\}$. Similarly as in proof of Theorem 3.1, we note that $\Omega \subset H_{n}$ for all $n \in \mathbb{N} \cup\{0\}$. Next, we show by induction that $\Omega \subset H_{n} \cap W_{n}$ for all $n \in \mathbb{N} \cup\{0\}$. From $W_{0}=C$, we note that $\Omega \subset H_{0} \cap W_{0}$. Suppose that $\Omega \subset H_{k} \cap W_{k}$ for some $k \in \mathbb{N} \cup\{0\}$. Then there exists $x_{k+1} \in H_{k} \cap W_{k}$ such that $x_{k+1}=\Pi_{H_{k} \cap W_{k}} x$. From the definition of $x_{k+1}$, we have

$$
\left\langle x_{k+1}-z, J x-J x_{k+1}\right\rangle \geq 0
$$


for all $z \in H_{k} \cap W_{k}$. Since $\Omega \subset H_{k} \cap W_{k}$, we have

$$
\left\langle x_{k+1}-z, J x-J x_{k+1}\right\rangle \geq 0, \quad \forall z \in \Omega
$$

and hence $z \in W_{k+1}$. So, we have $\Omega \subset W_{k+1}$ and therefore, $\Omega \subset H_{k+1} \cap W_{k+1}$. Hence $\Omega \subset$ $H_{n} \cap W_{n}$ for all $n \in \mathbb{N} \cup\{0\}$. This implies that $\left\{x_{n}\right\}$ is well defined. By the same argument as in proof of Theorem 3.1, we can prove that the sequence $\left\{x_{n}\right\}$ converges strongly to $\Pi_{\Omega} x$.

Setting $S_{n} \equiv S$ in Theorem 3.5, we have the following result.

Corollary 3.6 (Takahashi and Zembayashi [12, Theorem 3.1]). Let E be a uniformly convex and uniformly smooth Banach space; let $C$ be a nonempty closed convex subset of $E$. Let $f$ be a bifunction from $C \times C$ to $\mathbb{R}$ satisfying (A1)-(A4), and let $S$ be a relatively nonexpansive mapping from $C$ into itself such that $F(S) \cap \mathrm{EP}(f) \neq \emptyset$. Let $\left\{x_{n}\right\}$ be a sequence generated by

$$
\begin{gathered}
x_{0}=x \in C, \\
y_{n}=J^{-1}\left(\alpha_{n} J x_{n}+\left(1-\alpha_{n}\right) J S x_{n}\right), \\
u_{n} \in C \text { such that } f\left(u_{n}, y\right)+\frac{1}{r_{n}}\left\langle y-u_{n}, J u_{n}-J y_{n}\right\rangle \geq 0, \quad \forall y \in C, \\
H_{n}=\left\{z \in C: \phi\left(z, u_{n}\right) \leqslant \phi\left(z, x_{n}\right)\right\}, \\
W_{n}=\left\{z \in C:\left\langle x_{n}-z, J x-J x_{n}\right\rangle \geq 0\right\}, \\
x_{n+1}=\Pi_{H_{n} \cap W_{n}} x,
\end{gathered}
$$

for every $n \in \mathbb{N} \cup\{0\}$, where $J$ is the duality mapping on $E,\left\{\alpha_{n}\right\} \in[0,1]$ satisfies $\lim _{\inf _{n \rightarrow \infty}} \alpha_{n}(1-$ $\left.\alpha_{n}\right)>0$ and $\left\{r_{n}\right\} \subset[a, \infty)$ for some $a>0$. Then, $\left\{x_{n}\right\}$ converges strongly to $\Pi_{F(S) \cap \mathrm{EP}(f)} x$, where $\Pi_{F(S) \cap \mathrm{EP}(f)}$ is the generalized projection of $E$ onto $F(S) \cap \mathrm{EP}(f)$.

\section{Applications}

In this section, we apply our result to the problem of finding a common element of an equilibrium problem and the problem of finding a zero of a maximal monotone operator in a Banach space by using the shrinking projection method.

Let $E$ be a real Banach space. An operator $T \subset E \times E^{*}$ is said to be monotone if $\left\langle x-y, x^{*}-\right.$ $\left.y^{*}\right\rangle \geq 0$ whenever $\left(x, x^{*}\right),\left(y, y^{*}\right) \in T$. We denote the set $\{x \in E: 0 \in T x\}$ by $T^{-1} 0$. A monotone $T$ is said to be maximal if its graph $G(T)=\{(x, y): y \in T x\}$ is not properly contained in the graph of any other monotone operator. If $T$ is maximal monotone, then the solution set $T^{-1} 0$ is closed and convex.

Let $E$ be a smooth, strictly convex and reflexive Banach space, and let $T \subset E \times E^{*}$ be a maximal monotone operator. Then for each $\lambda>0$ and $x \in E$, there corresponds a unique element $x_{\lambda} \in D(T)$ satisfying

$$
J(x) \in J\left(x_{\curlywedge}\right)+\lambda T\left(x_{\curlywedge}\right)
$$


see Barbu [28] or Takahashi [4]. We define the resolvent of $T$ by $J_{\lambda} x=x_{\lambda}$. In other words, $J_{\lambda}=(J+\lambda T)^{-1} J$ for all $\lambda>0$. We know that $J_{\lambda}$ is relatively nonexpansive and $T^{-1} 0=F\left(J_{\lambda}\right)$ for all $\lambda>0$ (see $[4,17]$ ), where $F\left(J_{\lambda}\right)$ denotes the set of all fixed points of $J_{\lambda}$. We can also define, for each $\lambda>0$, the Yosida approximation of $T$ by $A_{\curlywedge}=\lambda^{-1}\left(J-J J_{\curlywedge}\right)$. We know that $\left(J_{\curlywedge} x, A_{\curlywedge} x\right) \in T$ for all $\lambda>0$.

We now consider the strong convergence theorem for finding a common element of the solution set of an equilibrium problem and the problem of finding a zero of a maximal monotone operator.

Theorem 4.1. Let $E$ be a uniformly convex and uniformly smooth Banach space. Let $T \subset E \times E^{*}$ be a maximal monotone operator, and let $J_{\lambda}=(J+\lambda T)^{-1} J$ for all $\lambda>0$. Let $C$ be a nonempty closed convex subset of $E$ such that $D(T) \subset C \subset J^{-1}\left(\bigcap_{\lambda>0} R(J+\lambda T)\right)$. Let $f$ be a bifunction from $C \times C$ to $\mathbb{R}$ satisfying $(A 1)-(A 4)$ with $\Omega:=\mathrm{EP}(f) \cap T^{-1} 0 \neq \emptyset$. Let $\left\{x_{n}\right\}$ be a sequence generated by $x_{0}=x \in C, C_{0}=C$, and

$$
\begin{gathered}
y_{n}=J^{-1}\left(\alpha_{n} J x_{n}+\left(1-\alpha_{n}\right) J J_{\lambda_{n}} x_{n}\right), \\
u_{n} \in C \text { such that } f\left(u_{n}, y\right)+\frac{1}{r_{n}}\left\langle y-u_{n}, J u_{n}-J y_{n}\right\rangle \geq 0, \quad \forall y \in C, \\
C_{n+1}=\left\{z \in C_{n}: \phi\left(z, u_{n}\right) \leqslant \phi\left(z, x_{n}\right)\right\}, \\
x_{n+1}=\prod_{C_{n+1}} x,
\end{gathered}
$$

for every $n \in \mathbb{N} \cup\{0\}$, where $J$ is the duality mapping on $E,\left\{\alpha_{n}\right\} \subset[0,1],\left\{\lambda_{n}\right\} \in(0, \infty)$ satisfy $\liminf _{n \rightarrow \infty} \alpha_{n}\left(1-\alpha_{n}\right)>0, \liminf _{n \rightarrow \infty} \lambda_{n}>0$, and $\left\{r_{n}\right\} \subset[a, \infty)$ for some $a>0$. Then $\left\{x_{n}\right\}$ converges strongly to $\Pi_{\Omega} x$, where $\Pi_{\Omega}$ is the generalized projection of $E$ onto $\Omega:=\operatorname{EP}(f) \cap T^{-1} 0$.

Proof. Let $\left\{z_{n}\right\}$ be a bounded sequence in $C$ such that $\lim _{n \rightarrow \infty}\left\|z_{n+1}-z_{n}\right\|=\lim _{n \rightarrow \infty} \| z_{n}-$ $J_{\lambda_{n}} z_{n} \|=0$, and let $z \in \omega_{w}\left(z_{n}\right)$. Then, there exists a subsequence $\left\{z_{n_{k}}\right\}$ of $\left\{z_{n}\right\}$ such that $z_{n_{k}} \rightarrow z$. By the uniform smoothness of $E$, we have

$$
\lim _{n \rightarrow \infty}\left\|J z_{n}-J J_{\lambda_{n}} z_{n}\right\|=0
$$

Since $\lim \inf _{n \rightarrow \infty} \lambda_{n}>0$, we have

$$
\lim _{n \rightarrow \infty}\left\|A_{\lambda_{n}} z_{n}\right\|=\lim _{n \rightarrow \infty} \frac{1}{\lambda_{n}}\left\|J z_{n}-J J_{\lambda_{n}} z_{n}\right\|=0 .
$$

Let $\left(u, u^{*}\right) \in T$. Then it holds from the monotonicity of $T$ that

$$
\left\langle u-J_{\lambda_{n_{k}}} z_{n_{k}}, u^{*}-A_{\lambda_{n_{k}}} z_{n_{k}}\right\rangle \geq 0
$$

for all $k \in \mathbb{N}$. Letting $k \rightarrow \infty$, we get $\left\langle u-z, u^{*}\right\rangle \geq 0$. Then, the maximality of $T$ implies $z \in T^{-1} 0:=\bigcap_{n=1}^{\infty} F\left(J_{\lambda_{n}}\right)$. Hence by Theorem 3.1, $\left\{x_{n}\right\}$ converges strongly to $\Pi_{\Omega} x$.

In case $C=E$. Putting $f(x, y)=0$ for all $x, y \in E$ and $r_{n}=1$ in Theorem 4.1, we obtain the following corollary. 
Corollary 4.2. Let $E$ be a uniformly convex and uniformly smooth Banach space. Let $T \subset E \times E^{*}$ be a maximal monotone operator, and let $J_{\lambda}=(J+\lambda T)^{-1} J$ for all $\lambda>0$, with $T^{-1} 0 \neq \emptyset$. Let $\left\{x_{n}\right\}$ be a sequence generated by $x_{0}=x \in E, C_{0}=E$, and

$$
\begin{gathered}
y_{n}=J^{-1}\left(\alpha_{n} J x_{n}+\left(1-\alpha_{n}\right) J J_{\lambda_{n}} x_{n}\right), \\
C_{n+1}=\left\{z \in C_{n}: \phi\left(z, y_{n}\right) \leqslant \phi\left(z, x_{n}\right)\right\}, \\
x_{n+1}=\prod_{C_{n+1}} x,
\end{gathered}
$$

for every $n \in \mathbb{N} \cup\{0\}$, where $J$ is the duality mapping on $E,\left\{\alpha_{n}\right\} \subset[0,1],\left\{\lambda_{n}\right\} \in(0, \infty)$ satisfy $\liminf _{n \rightarrow \infty} \alpha_{n}\left(1-\alpha_{n}\right)>0$, $\liminf _{n \rightarrow \infty} \lambda_{n}>0$. Then $\left\{x_{n}\right\}$ converges strongly to $\Pi_{\Omega} x$, where $\Pi_{\Omega}$ is the generalized projection of $E$ onto $\Omega:=T^{-1} 0$.

Similarly as in the proof of Theorem 4.1, we can prove the following theorem.

Theorem 4.3. Let $E$ be a uniformly convex and uniformly smooth Banach space. Let $T \subset E \times E^{*}$ be a maximal monotone operator and let $J_{\lambda}=(J+\lambda T)^{-1} J$ for all $\lambda>0$. Let $C$ be a nonempty closed convex subset of $E$ such that $D(T) \subset C \subset J^{-1}\left(\bigcap_{\lambda>0} R(J+\lambda T)\right)$. Let $f$ be a bifunction from $C \times C$ to $\mathbb{R}$ satisfying $(A 1)-(A 4)$ with $\Omega:=\mathrm{EP}(f) \cap T^{-1} 0 \neq \emptyset$. Let $\left\{x_{n}\right\}$ be a sequence generated by $x_{0}=x \in C$ and

$$
\begin{gathered}
y_{n}=J^{-1}\left(\alpha_{n} J x_{n}+\left(1-\alpha_{n}\right) J J_{\lambda_{n}} x_{n}\right), \\
u_{n} \in C \text { such that } f\left(u_{n}, y\right)+\frac{1}{r_{n}}\left\langle y-u_{n}, J u_{n}-J y_{n}\right\rangle \geq 0, \quad \forall y \in C, \\
H_{n}=\left\{z \in C: \phi\left(z, u_{n}\right) \leqslant \phi\left(z, x_{n}\right)\right\}, \\
W_{n}=\left\{z \in C:\left\langle x_{n}-z, J x-J x_{n}\right\rangle \geq 0\right\}, \\
x_{n+1}=\Pi_{H_{n} \cap W_{n}} x,
\end{gathered}
$$

for every $n \in \mathbb{N} \cup\{0\}$, where $J$ is the duality mapping on $E,\left\{\alpha_{n}\right\} \subset[0,1],\left\{\lambda_{n}\right\} \in(0, \infty)$ satisfy $\liminf _{n \rightarrow \infty} \alpha_{n}\left(1-\alpha_{n}\right)>0, \liminf _{n \rightarrow \infty} \lambda_{n}>0$, and $\left\{r_{n}\right\} \subset[a, \infty)$ for some $a>0$. Then $\left\{x_{n}\right\}$ converges strongly to $\Pi_{\Omega} x$, where $\Pi_{\Omega}$ is the generalized projection of $E$ onto $\Omega:=\operatorname{EP}(f) \cap T^{-1} 0$.

Corollary 4.4. Let E be a uniformly convex and uniformly smooth Banach space. Let $T \subset E \times E^{*}$ be a maximal monotone operator and let $J_{\lambda}=(J+\lambda T)^{-1} J$ for all $\lambda>0$, with $T^{-1} 0 \neq \emptyset$. Let $\left\{x_{n}\right\}$ be a sequence generated by $x_{0}=x \in E$ and

$$
\begin{gathered}
y_{n}=J^{-1}\left(\alpha_{n} J x_{n}+\left(1-\alpha_{n}\right) J J_{\lambda_{n}} x_{n}\right), \\
H_{n}=\left\{z \in C: \phi\left(z, y_{n}\right) \leqslant \phi\left(z, x_{n}\right)\right\}, \\
W_{n}=\left\{z \in C:\left\langle x_{n}-z, J x-J x_{n}\right\rangle \geq 0\right\}, \\
x_{n+1}=\Pi_{H_{n} \cap W_{n}} x,
\end{gathered}
$$


for every $n \in \mathbb{N} \cup\{0\}$, where $J$ is the duality mapping on $E,\left\{\alpha_{n}\right\} \subset[0,1],\left\{\lambda_{n}\right\} \in(0, \infty)$ satisfy $\liminf _{n \rightarrow \infty} \alpha_{n}\left(1-\alpha_{n}\right)>0, \liminf _{n \rightarrow \infty} \lambda_{n}>0$. Then $\left\{x_{n}\right\}$ converges strongly to $\Pi_{\Omega} x$, where $\Pi_{\Omega}$ is the generalized projection of $E$ onto $\Omega:=T^{-1} 0$.

\section{Acknowledgments}

The first author thanks the National Research Council of Thailand to Naresuan University, 2009 for the financial support. Moreover, the second author would like to thank the National Centre of Excellence in Mathematics, PERDO, under the Commission on Higher Education, Ministry of Education, Thailand. This work is dedicated to Professor Wataru Takahashi on his retirement.

\section{References}

[1] E. Blum and W. Oettli, "From optimization and variational inequalities to equilibrium problems," The Mathematics Student, vol. 63, no. 1-4, pp. 123-145, 1994.

[2] P. L. Combettes and S. A. Hirstoaga, "Equilibrium programming in Hilbert spaces," Journal of Nonlinear and Convex Analysis, vol. 6, no. 1, pp. 117-136, 2005.

[3] A. Moudafi, "Second-order differential proximal methods for equilibrium problems," Journal of Inequalities in Pure and Applied Mathematics, vol. 4, no. 1, article 18, p. 7, 2003.

[4] W. Takahashi, Convex Analysis and Approximation Fixed Points, vol. 2 of Mathematical Analysis Series, Yokohama Publishers, Yokohama, Japan, 2000.

[5] L.-C. Ceng and J.-C. Yao, "Hybrid viscosity approximation schemes for equilibrium problems and fixed point problems of infinitely many nonexpansive mappings," Applied Mathematics and Computation, vol. 198, no. 2, pp. 729-741, 2008.

[6] L.-C. Ceng and J.-C. Yao, "A hybrid iterative scheme for mixed equilibrium problems and fixed point problems," Journal of Computational and Applied Mathematics, vol. 214, no. 1, pp. 186-201, 2008.

[7] L.-C. Ceng, S. Schaible, and J.-C. Yao, "Implicit iteration scheme with perturbed mapping for equilibrium problems and fixed point problems of finitely many nonexpansive mappings," Journal of Optimization Theory and Applications, vol. 139, no. 2, pp. 403-418, 2008.

[8] L.-C. Ceng, A. Petruşel, and J.-C. Yao, "Iterative approaches to solving equilibrium problems and fixed point problems of infinitely many nonexpansive mappings," Journal of Optimization Theory and Applications, vol. 143, no. 1, pp. 37-58, 2009.

[9] J.-W. Peng and J.-C. Yao, "Strong convergence theorems of iterative scheme based on the extragradient method for mixed equilibrium problems and fixed point problems," Mathematical and Computer Modelling, vol. 49, no. 9-10, pp. 1816-1828, 2009.

[10] S. Plubtieng and R. Punpaeng, "A general iterative method for equilibrium problems and fixed point problems in Hilbert spaces," Journal of Mathematical Analysis and Applications, vol. 336, no. 1, pp. 455$469,2007$.

[11] S. Plubtieng and R. Punpaeng, "A new iterative method for equilibrium problems and fixed point problems of nonexpansive mappings and monotone mappings," Applied Mathematics and Computation, vol. 197, no. 2, pp. 548-558, 2008.

[12] W. Takahashi and K. Zembayashi, "Strong and weak convergence theorems for equilibrium problems and relatively nonexpansive mappings in Banach spaces," Nonlinear Analysis: Theory, Methods $\mathcal{E}$ Applications, vol. 70, no. 1, pp. 45-57, 2009.

[13] W. Takahashi and K. Zembayashi, "Strong convergence theorem by a new hybrid method for equilibrium problems and relatively nonexpansive mappings," Fixed Point Theory and Applications, vol. 2008, Article ID 52846, 11 pages, 2008.

[14] K. Nakajo and W. Takahashi, "Strong convergence theorems for nonexpansive mappings and nonexpansive semigroups," Journal of Mathematical Analysis and Applications, vol. 279, no. 2, pp. 372379, 2003.

[15] S. Kamimura and W. Takahashi, "Strong convergence of a proximal-type algorithm in a Banach space," SIAM Journal on Optimization, vol. 13, no. 3, pp. 938-945, 2002.

[16] C. Martinez-Yanes and H.-K. Xu, "Strong convergence of the CQ method for fixed point iteration processes," Nonlinear Analysis: Theory, Methods E Applications, vol. 64, no. 11, pp. 2400-2411, 2006. 
[17] S. Matsushita and W. Takahashi, "A strong convergence theorem for relatively nonexpansive mappings in a Banach space," Journal of Approximation Theory, vol. 134, no. 2, pp. 257-266, 2005.

[18] J.-W. Peng and J.-C. Yao, "A modified CQ method for equilibrium problems, fixed points and variational inequality," Fixed Point Theory, vol. 9, no. 2, pp. 515-531, 2008.

[19] J.-W. Peng and J.-C. Yao, “A new hybrid-extragradient method for generalized mixed equilibrium problems, fixed point problems and variational inequality problems," Taiwanese Journal of Mathematics, vol. 12, no. 6, pp. 1401-1432, 2008.

[20] S. Plubtieng and K. Ungchittrakool, "Strong convergence theorems for a common fixed point of two relatively nonexpansive mappings in a Banach space," Journal of Approximation Theory, vol. 149, no. 2, pp. 103-115, 2007.

[21] W. Takahashi, Y. Takeuchi, and R. Kubota, "Strong convergence theorems by hybrid methods for families of nonexpansive mappings in Hilbert spaces," Journal of Mathematical Analysis and Applications, vol. 341, no. 1, pp. 276-286, 2008.

[22] K. Aoyama, Y. Kimura, W. Takahashi, and M. Toyoda, “Approximation of common fixed points of a countable family of nonexpansive mappings in a Banach space," Nonlinear Analysis: Theory, Methods $\mathcal{E}$ Applications, vol. 67, no. 8, pp. 2350-2360, 2007.

[23] Ya. I. Alber, "Metric and generalized projection operators in Banach spaces: properties and applications," in Theory and Applications of Nonlinear Operators of Accretive and Monotone Type, A. G. Kartsatos, Ed., vol. 178 of Lecture Notes in Pure and Applied Mathematics, pp. 15-50, Marcel Dekker, New York, NY, USA, 1996.

[24] H. K. Xu, "Inequalities in Banach spaces with applications," Nonlinear Analysis: Theory, Methods $\mathcal{E}$ Applications, vol. 16, no. 12, pp. 1127-1138, 1991.

[25] C. Zălinescu, "On uniformly convex functions," Journal of Mathematical Analysis and Applications, vol. 95, no. 2, pp. 344-374, 1983.

[26] C. Zălinescu, Convex Analysis in General Vector Spaces, World Scientific, River Edge, NJ, USA, 2002.

[27] K. Nakajo, K. Shimoji, and W. Takahashi, "On strong convergence by the hybrid method for families of mappings in Hilbert spaces," Nonlinear Analysis: Theory, Methods $\mathcal{E}$ Applications, vol. 71, no. 1-2, pp. 112-119, 2009.

[28] V. Barbu, Nonlinear Semigroups and Differential Equations in Banach Spaces, Editura Academiei Republicii Socialiste România, Bucharest, Romania, 1976. 